\title{
Erratum to: The neuroanatomical phenotype of tuberous sclerosis complex: focus on radial migration lines
}

\author{
Agnies M. van Eeghen • Laura Ortiz-Terán • \\ Jason Johnson • Margaret B. Pulsifer • \\ Elizabeth A. Thiele $\cdot$ Paul Caruso
}

Published online: 18 June 2013

(C) Springer-Verlag Berlin Heidelberg 2013

\section{Erratum to: Neuroradiology}

DOI 10.1007/s00234-013-1184-3

Unfortunately, one of the authors name, Laura Ortiz-Terán, was incorrectly listed as Terán LO instead of L Ortiz-Terán in the original publication of this paper.

The online version of the original article can be found at http://dx.doi.org/ 10.1007/s00234-013-1184-3.

A. M. van Eeghen $(\varangle) \cdot$ E. A. Thiele

Department of Neurology, Carol and James Herscot Center for Tuberous Sclerosis Complex, Massachusetts General Hospital,

175 Cambridge Street,

Boston, MA 02114, USA

e-mail: avaneeghen@partners.org

\section{A. M. van Eeghen}

ENCORE, Expertise Centre for Neurodevelopmental Disorders, Department of Neuroscience, Erasmus Medical Centre,

Rotterdam, The Netherlands

L. Ortiz-Terán $\cdot$ J. Johnson $\cdot$ P. Caruso

Department of Radiology, Massachusetts General Hospital,

Boston, MA, USA

M. B. Pulsifer

Department of Psychiatry, Psychological Assessment Center,

Massachusetts General Hospital, Boston, MA, USA 